\title{
Chapter 6 \\ Future Energy Demand Developments and Demand Side Flexibility in a Decarbonized Centralized Energy System
}

\author{
Andrea Herbst, Anna-Lena Klingler, Stephanie Heitel, Pia Manz, \\ Tobias Fleiter, Matthias Rehfeldt, Francesca Fermi, Davide Fiorello, \\ Angelo Martino, and Ulrich Reiter
}

\begin{abstract}
European final energy consumption mainly stems from five sectors: transport, households, industry, residential, and agriculture using fossil fuels as dominant energy carriers. In order to achieve the climate targets, emissions in the demand sectors must be drastically reduced. Due to different characteristics and challenges each sector needs its own strategy how to achieve such decarbonization until 2050. In the following chapter, the impacts of an ambitious mitigation scenario on future energy demand and $\mathrm{CO}_{2}$ emissions for transport, industry, residential, and tertiary are analyzed discussing sector specific decarbonization strategies and mitigation options. Implications of such strategies for demand-side flexibility and its future need are analyzed.
\end{abstract}

\footnotetext{
A. Herbst $(\varangle) \cdot$ A.-L. Klingler $\cdot$ S. Heitel · P. Manz · T. Fleiter · M. Rehfeldt Competence Center Energy Technology and Energy Systems, Fraunhofer Institute for Systems and Innovation Research ISI, Karlsruhe, Germany

e-mail: andrea.herbst@isi.fraunhofer.de

F. Fermi · D. Fiorello - A. Martino

TRT Trasporti e Territorio, Milan, Italy

U. Reiter

TEP Energy GmbH, Zurich, Switzerland
}

\author{
A.-L. Klingler \\ Business Area Mobility and Urban Systems Engineering, Fraunhofer Institute for Industrial \\ Engineering IAO, Stuttgart, Germany \\ S. Heitel \\ Competence Center Sustainability and Infrastructure Systems, Fraunhofer Institute for Systems \\ and Innovation Research ISI, Karlsruhe, Germany
}




\subsection{Introduction}

European final energy consumption can be divided in five main sectors: transport, households, industry, residential, and agriculture. The transport sector accounts for $31 \%$ of EU final energy demand followed by the residential sector with $27 \%$, the industry sector with $25 \%$ and the tertiary sector with $15 \%$ of final energy consumption in the year 2017. The dominant energy carriers currently used are oil \& petroleum products (37\%), natural gas (23\%), and electricity (23\%) as well as renewable energy sources \& biofuels (10\%) (Eurostat 2017). Within the sectors the energy carrier mix varies depending on the structure and the specific requirements of the sectors. Transport energy demand is substantially dominated by fossil fuels (oil, petroleum, and natural gas) covering about 95\%, with minor use of biofuels (4\%) and electricity (1\%) (European Commission 2017). Residential demand mainly stems from residential heating purposes $(80 \%)$ which are provided via the use of natural gas, fuel oil, and electricity. Electricity demand for appliances \& processes as well as demand for heating and cooling purposes in buildings lead to an energy carrier mix in the tertiary sector, which is dominated by the use of electricity and natural gas. In industry, final energy demand is dominated by the use of natural gas, coal, oil, and electricity for energy-intensive production processes like steel, cement, or basic chemical production.

The European Commission's recently published long-term strategy (European Commission 2016) shows that emissions in the demand sectors must be drastically reduced in order to achieve the climate targets. However, as the sectors considered are very heterogeneous, so are the respective challenges for decarbonization. As the transport sector was not able to decrease GHG emissions within the last decades due to a strongly increasing transport activity, a combination of three main strategies seems required to meet the challenge of decarbonization: (i) increasing the efficiency of the transport system including a shift to lower emission transport modes, (ii) speeding up the deployment of low-emission alternative energy such as advanced biofuels, electricity, hydrogen and renewable synthetic fuels, and (iii) accelerating the transition toward zero-emission vehicles.

The residential and tertiary sector face large challenges due to the high need of thermal renovation of the existing building stock as well as efficient new construction. Main challenges in the industry sector include the mitigation of process emissions from chemical reactions within the productions process, high-temperature needs and technical restrictions in industrial furnaces for the use of RES as well as feedstock demands for the chemical industry (currently mainly fossil-based).

In the following, the impacts of an ambitious mitigation scenario on future energy demand and $\mathrm{CO}_{2}$ emissions for transport, industry, residential, and tertiary as well as its implications for demand-side flexibility are analyzed. 


\subsection{Scenario Assumptions and Model Coupling}

The demand-side aspects of an ambitious mitigation scenario "well below $2{ }^{\circ} \mathrm{C}$ " correspond to an $80 \%$ emissions reduction of the entire system excluding carbon sinks and can be translated into sectoral carbon reduction targets for transport (61-63\%), residential (87-91\%), tertiary (88-93\%), and industry (75-85\%) (European Commission 2018). The considered mitigation scenario reflects a centralized energy system, which is characterized by external supply of RES secondary energy carriers and centralized district heating systems. The High-RES centralized scenario is analyzed in comparison to a reference scenario (Mod-RES) reflecting a current policy case based on known policies and observed trends (cf. Chapter 2). Important sector specific scenario assumptions can be summarized as shown in Table 6.1.

The results and analysis shown in the following sections have been carried out using three different types of models:

- the long-term bottom-up simulation model FORECAST: calculating annual future residential, tertiary and industrial energy demand and $\mathrm{CO} 2$ emissions on country level taking into account sector characteristics as well as a high level of technological detail (Fleiter et al. 2018; Herbst et al. 2017; Elsland 2017; Jakob et al. 2013);

- the long-term system dynamics simulation model ASTRA: calculating annual future transport energy demand and $\mathrm{CO} 2$ emissions on country level covering a wide range of transport measures and policies as well as alternative powertrain technologies for road vehicles (Schade et al. 2018; Fermi et al. 2014; Heitel et al. 2018);

- and the hourly electricity load curve adjustment model eLOAD: estimating the long-term evolution of the electricity system load curves on country level due to structural changes and new appliances as well as demand response activities (Klingler 2018; Gnann et al. 2018).

A detailed description of the used models and scenario assumptions can be found in Chapters 2 and 3.

\subsection{Future Energy Demand and $\mathrm{CO}_{2}$ Emissions}

To achieve an ambitious mitigation level, major changes in the demand sectors have to take place in the medium and long-term. In addition to energy efficiency, another important pillar for a low-carbon demand-side transformation is fuel switch from fossil fuels (e.g., coal, natural gas, oil) to renewable energy sources (e.g., biomass, solar). However, energy efficiency and switching to renewables is likely not sufficient to achieve deep decarbonization especially for industry and transport (European Commission 2018). These sectors need additional strategies for significant emission 
Table 6.1 Scenario characterization by sector

\begin{tabular}{|c|c|}
\hline Mod-RES & High-RES centralized \\
\hline \multicolumn{2}{|l|}{ Transport } \\
\hline $\begin{array}{l}\text { Targets and actions according to currently } \\
\text { implemented European regulations }\end{array}$ & $\begin{array}{l}\text { Policies to promote sustainable mobility, } \\
\text { efficiency improvements, and multimodality } \\
\text { More ambitious and extended } \mathrm{CO}_{2} \text { standards } \\
\text { for new vehicles of all road modes } \\
\text { Increased fuel tax for conventional fuels } \\
\text { Further expansion of filling and charging } \\
\text { infrastructure for electric mobility } \\
\text { Sales ban of new pure internal combustion } \\
\text { engine vehicles (urban buses: 2035, cars: } 2040 \text { ) } \\
\text { Diffusion of fuel cell (FC) electric trucks based } \\
\text { on R\&D for FC technology, deployment of } \\
\text { hydrogen (H2) infrastructure with centralized } \\
\text { H2 production in large plants }\end{array}$ \\
\hline
\end{tabular}

\section{Residential/Tertiary}

Building standards according to currently implemented national regulations Renovation rates remain on current level Implemented national incentives and subsidies for heating technologies stay in force Ecodesign directive in today's implementation $\&$ further announced reinforcement
Higher building standards, compliance, \& financial incentives Increase in renovation rates

Financial incentives for alternative heating systems

Ban of oil boilers after 2030 in the residential sector

Fuel tax on gas \& oil

Decrease in average lifetime of heating systems New efficiency classes \& more products included in the Ecodesign directive after 2025

\section{Industry}

EE progress according to current policies Fuel switch driven by energy \& $\mathrm{CO}_{2}$ prices
Faster diffusion of incremental process improvements. Innovative/radical process improvements

Centralized hydrogen production off-site Financial support for RES technologies Increased recycling and material efficiency/substitution

reductions, as for example the use of secondary energy sources such as electricity and hydrogen.

A possible pathway for decarbonizing European demand is reflected in the HighRES centralized scenario (Fig. 6.1). In 2050 electricity becomes the dominant energy due to high electrification in all sectors (e.g., electrification of passenger transport by diffusion of battery electric and plug-in hybrid vehicles, the use of electric furnaces in industry, and high penetration of heat pumps in the tertiary and residential sector), this leads to an overall increase in electricity demand by $36 \%$ compared to 2015 , from 2,732 to 3,706 TWh in 2050 , which has to be provided from renewable energy sources. In addition to electricity, hydrogen as another secondary energy carrier based 

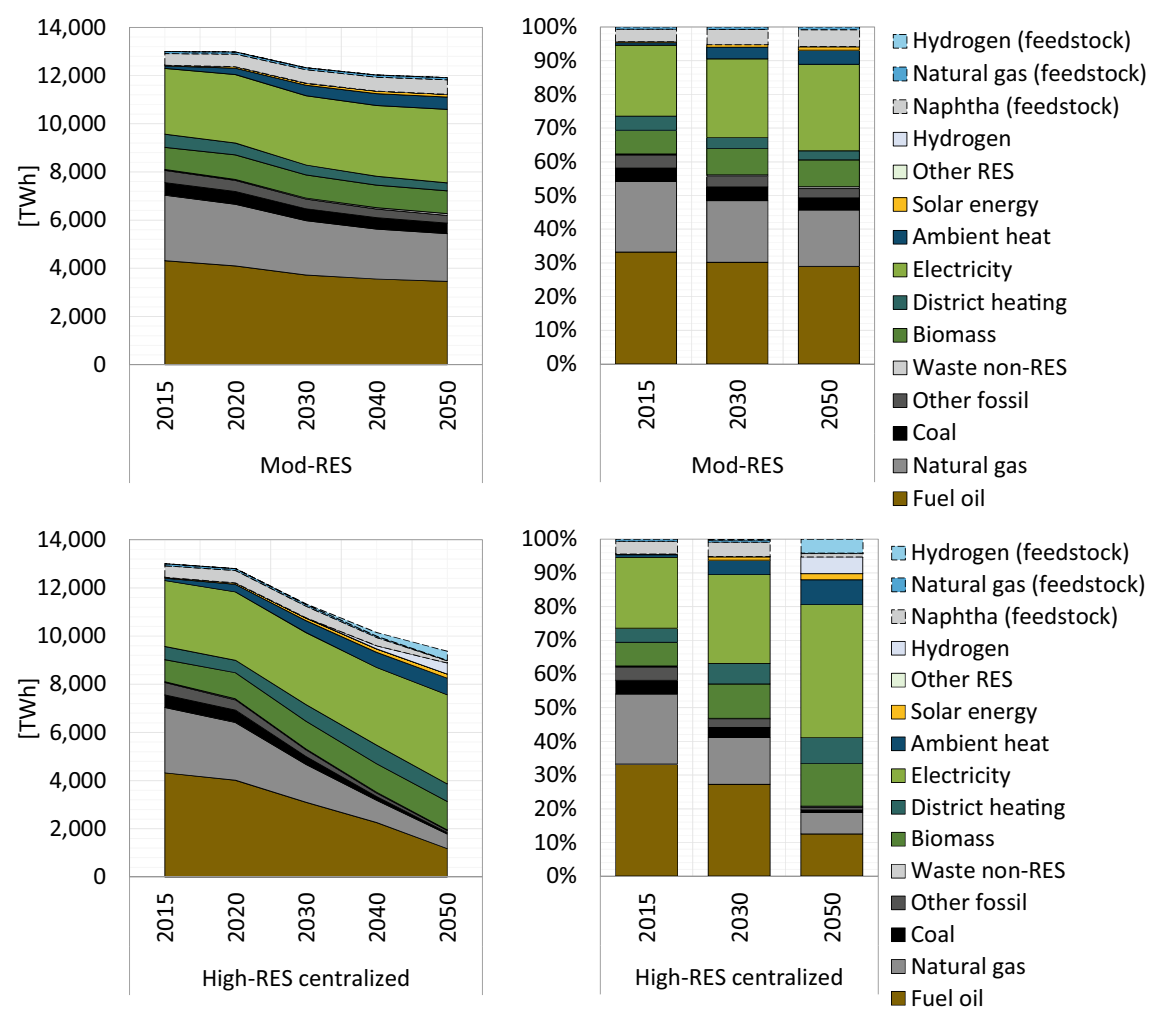

Fig. 6.1 EU-27 and UK final energy demand by energy carrier and scenario in TWh (2015-2050) (Source Own illustration)

on a $\mathrm{CO}_{2}$-neutral production, e.g., via renewable energy sources, gains importance after 2030. Based on the model calculation, $845 \mathrm{TWh}$ are needed in the transport in 2050 (418 TWh mainly for fuel cell electric trucks) and industry sector (427 TWh of which $384 \mathrm{TWh}$ are used for feedstock production in the chemical industry). Biomass use is increasing by 269 TWh compared to 2015 caused by additional demand for biokerosene in aviation for the transport sector. Due to lower cost for centralized heat generation, the demand for district heating is increasing by $32 \%$ compared to 2015 , from 549 to $723 \mathrm{TWh}$ in 2050 . The remaining demand for fossil fuels primarily stems from uses in the transport sector -1,205 TWh mainly from oil-based fuels-and the industry sector-470 TWh of which $299 \mathrm{TWh}$ are natural gas. In the tertiary and residential sector 246 TWh of fossil fuels, mainly gas, are used in 2050.

This fuel switch is accompanied by high increases in energy efficiency in all sectors leading to an overall demand reduction of $28 \%$ compared to 2015 , from $13,003 \mathrm{TWh}$ to 9,376 TWh in 2050 (including the demand for feedstock in the chemical industry). Efficiency gains in the transport sector mainly stem from increased efficiency of vehicles, supported by modal shift of road transport demand to rail, public transport, 
Table 6.2 EU-27 and UK direct $\mathrm{CO}_{2}$ emissions by scenario and sector

\begin{tabular}{l|l|l|l|l}
\hline Scenario/sector & 2015 & 2050 & $\Delta 2015(\%)$ & $\Delta 1990(\%)$ \\
\hline Mod-RES & 2,218 & 1,818 & -18 & -29 \\
\hline Transport & 995 & 901 & -9 & +5 \\
\hline Residential & 317 & 204 & -36 & -41 \\
\hline Tertiary & 161 & 50 & -69 & -74 \\
\hline Industry & 745 & 663 & -11 & -44 \\
\hline High-RES centralized & 2,218 & 585 & -74 & -77 \\
\hline Transport & 995 & 336 & -66 & -61 \\
\hline Residential & 317 & 26 & -92 & -92 \\
\hline Tertiary & 161 & 26 & -84 & -87 \\
\hline Industry & 745 & 197 & -74 & -83 \\
\hline
\end{tabular}

Source Own illustration

and other modes. In the residential and tertiary sector higher building standards, increased compliance and financial incentives for alternative heating lead to a strong increase in renovation rates and energy efficiency improvements (e.g., old direct electric heating, water boilers, and night storage heaters are being replaced by more efficient heat pumps). In addition, new efficiency classes and the inclusion of more products in the Ecodesign Directive lead to further reductions in demand after 2025. Also in industry, an ambitious exploitation of remaining energy efficiency potentials takes place (e.g., near-net-shape casting in the steel industry, new drying techniques in the paper industry, and efficiency improvements in electric motor systems). However, potentials for further improvement in this sector are limited due to already efficient production technologies. The introduction of innovative production technologies (e.g., low-carbon cement, $\mathrm{RES} \mathrm{H}_{2}$ direct reduced steel, RES H2 methanol, and ammonia) lead to significant reductions in industrial $\mathrm{CO}_{2}$ emissions.

The high level of ambition in the High-RES decentralized scenario implies an overall direct emission reduction of 74\% compared to 2015 (Table 6.2). Remaining emissions in 2050 mainly stem from oil demand in the transport sector (319 Mt) as well as industrial process emissions (80 Mt) and natural gas demand (60 Mt).

\subsubsection{Decarbonizing the Transport Sector}

The transport sector is currently responsible for about a third of final energy consumption in EU-27 countries and UK (European Commission 2017). Therein, fuel oil products are the dominant energy carrier, constituting around $93 \%$ of total energy demand for transport in 2015.

Transport and mobility demand are key to determine future energy consumption. ASTRA estimates an increase in transport demand until 2050, mainly caused by 
economic and population growth expected in the future decades. Passenger transport demand is expected to increase by $34 \%$ and freight transport by $60 \%$ in the period between 2015 and 2050.

In the Mod-RES scenario, in which only already implemented European regulations are considered, the EU-27 and UK total final energy demand is expected to decrease by modest 3\% from 2015 to 2050, with fuel oil products still representing the main energy carrier (about $84 \%$ ). The slight decrease in energy demand can be observed from 2020 on, due to the implementation of policies enhancing the efficiency standards for cars and vans (cf. Fig. 6.2).

In the High-RES centralized scenario, total energy demand is decreasing strongly, about $30 \%$ from 2015 to 2050 , due to a modal shift from road transport to more efficient transport modes and substantial efficiency improvements in the vehicle fleet including new drive technologies. The composition of the energy carriers underwent a big change: the use of fuel oil represents about $40 \%$ of demand in 2050 while the remaining share is covered by electricity (22\%), hydrogen $(15 \%)$, and biofuels $(18 \%)$.
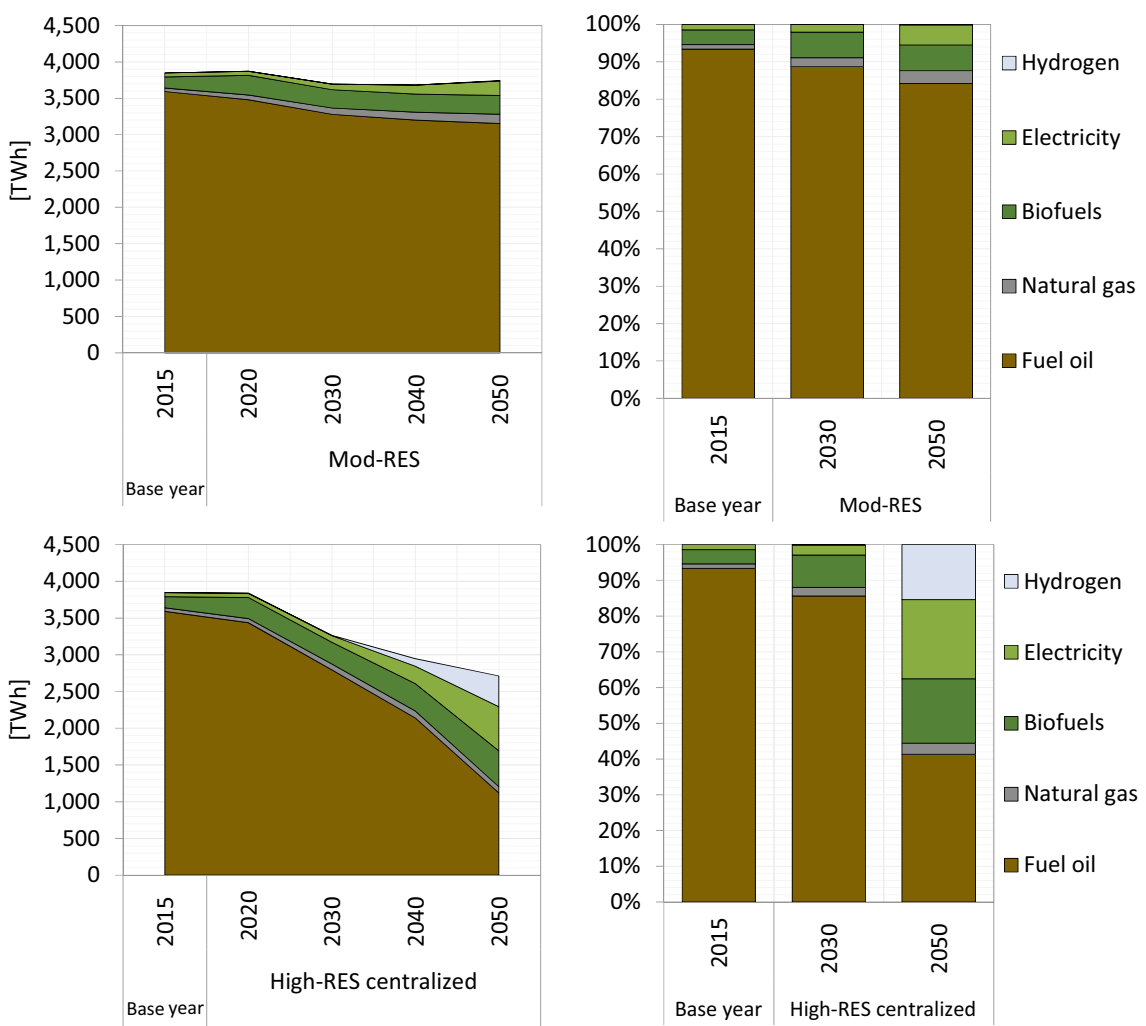

Fig. 6.2 EU-27 and UK final energy demand of the transport sector by energy carrier and scenario in TWh (2015-2050) (Source Own illustration) 
The strong increase in electricity and hydrogen demand results from a technological change for road vehicles. The electrification of passenger transport by diffusion of battery electric (BEV) and plug-in hybrid (PHEV) vehicles leads to a total annual electricity demand of $600 \mathrm{TWh}$ in 2050 , thus being ten times higher compared to 2015. The hydrogen demand reaches about 420 TWh per year in 2050 , driven by the market penetration of fuel cell electric trucks $(80 \%$ of the hydrogen demand for transport) and spillover effects to the diffusion of fuel cell (FC) technology for cars, vans, and buses. The triplication of biofuel demand from 2015 to 2050 is triggered mainly by air transport. It is assumed that $43 \%$ of aviation fuel demand is covered by biokerosene in 2050 to reduce the high carbon footprint of the aviation sector, which is constantly growing in terms of transport activity, leading to about $220 \mathrm{TWh}$ biokerosene demand.

\subsubsection{Modal Shift}

In general terms, rail transport, navigation, and public transport are more energy efficient compared to road transport (Faberi et al. 2015). Thus, shifts to these modes are preferable. Push and pull factors have to be combined, i.e., discouraging motorized road transport, e.g., by energy and vehicle taxation, parking space management, or road charging, and at the same time making non-road modes more attractive by investing in rail, cycling, and walking infrastructure, by improving public transport services and the availability of shared mobility, and by promoting multimodality with electronic information platforms and services that reduce waiting times, enable seamless electronic ticketing and real-time trip information.

Modal shifts for freight are difficult to obtain due to rare direct access to rail and waterways at origin and destination and thus required reloading operations. In the Mod-RES simulation, the modal share of road transport declines from $50 \%$ in 2015 by only $3 \%$ toward rail and ships to $47 \%$ in 2050 . In High-RES, an unintended rebound effect was even induced in later decades: Policies pushing the diffusion of zero-emission technologies make road freight transport a clean and attractive alternative, so that road share regains to $49 \%$ in 2050 . For passenger transport, a significant modal shift to public transport, car-sharing, and active modes like biking including e-bikes and walking was observed on the local level in the model.

\subsubsection{Energy Efficiency of Vehicles}

If motorized trips can neither be avoided nor shifted to more efficient transport modes, efficiency can be increased on the vehicle level. Efficiency improvements for road transport were achieved since 1990 with an average of $-0.7 \%$ per year for cars and about $-0.5 \%$ per year for trucks and light-duty vehicles (EEA 2019). The EU regulations on $\mathrm{CO}_{2}$ emission performance standards for cars and vans provide an indication of the expected efficiency improvements until 2030 (Regulation (EU) 2019/631, 2011/510 and 2009/443): until 2021, a target reduction of about $27 \%$ with 
respect to 2015 is required in terms of fuel efficiency for new car vehicles, while for 2025 and 2030 the manufacturers will have to comply with a further reduction target of $15 \%$ and $37 \%$ for new cars. Approaches for high efficiency of vehicles are reduced resistance, e.g., via aerodynamic designs, lightweight materials and small vehicles, brake energy recuperation, and improved traffic flow through traffic management, harmonized speeds, driver training, as well as respective effects of connected and autonomous driving (e.g., Helms et al. 2010; Krail et al. 2019).

\subsubsection{Diffusion of Low-/Zero-Emission Vehicles}

Efficiency improvements of road vehicles contribute to the decarbonization process but are not enough to achieve the GHG emission reduction target. Therefore, a substantial change of energy carriers from fossil fuels to electricity and hydrogen is needed through the diffusion of alternative drive technologies, in particular, battery electric vehicles, plug-in hybrid electric vehicles, and fuel cell electric vehicles. Their diffusion can be accelerated through measures like investments in charging and hydrogen infrastructure, tax incentives, tighter fuel efficiency standards and sales bans of new vehicles with conventional internal combustion engines. Drivers of the diffusion and resulting impacts for the energy system will be described more comprehensively in the chapter about disruptive technologies (cf. Chapter 7).

\subsubsection{Alternative Fuels}

Electricity-based synthetic fuels and biofuels are considered as a valuable decarbonization option for aviation and navigation that both lack mature alternative technologies and have long operation lifetimes of their crafts. Considering the relatively low efficiency of these alternative fuels from well-to-wheel as well as sustainability concerns of biofuels, increased use for road modes seems only reasonable in a transition phase. Biokerosene was approved for commercial use in 2011 and some airlines are experimenting with their use. Several studies confirm that the biokerosene blend can reduce air pollutant and GHG emissions (European Commission 2011). However, with current technologies, the target of halving the $\mathrm{CO}_{2}$ emissions by 2050 with respect to 2005 cannot be met (IATA 2015). Therefore, more advanced, sustainable biofuels of the second generation (i.e., not in competition with food crops for human consumption) and third-generation (based on algae) or electrolysis-based power-to- $\mathrm{X}$ fuels need to be further developed, tested and production capacities to be built up.

\subsubsection{Impact on $\mathrm{CO}_{2}$ Emissions}

Although the strategies modal shift, efficiency improvement of vehicles, diffusion of low- and zero-emission vehicles and alternative fuels are pursued in the businessas-usual scenario Mod-RES to a certain extent, their degree of implementation is far 
too low to meet the decarbonization target for the transport sector of $-60 \% \mathrm{GHG}$ emissions by 2050 compared to 1990 levels. The simulation of Mod-RES with ASTRA showed that only a small reduction of GHG emissions is achieved from 2015 levels (-9\%), with even a net increase from 1990 levels $(-7 \%)$, triggered by the consistently growing transport activity.

Therefore, a comprehensive set of policies and infrastructure deployment decisions acting on both technology diffusion and demand management are required to meet the target. Several combinations and forms of the presented strategies could be envisaged. With the measures assumed in the High-RES centralized scenario a decrease of transport $\mathrm{CO}_{2}$ emissions by $-61 \%$ was achieved, thus meeting the decarbonization target. The gap in model results for Mod-RES 2050 was closed in HighRES by policies that accelerate the diffusion of low- and zero-emission vehicles (further $-30 \% \mathrm{CO}_{2}$ emissions compared to Mod-RES 2050), policies increasing efficiency improvements $(-16 \%)$, biofuels $(-14 \%)$, and modal shift $(-14 \%)$. A sales ban of pure internal combustion engine cars in 2040 and a strong promotion of fuel cell electric trucks accelerate the technology change for road vehicles. Biofuels contribute in particular for decarbonization of aviation and navigation. Policies aiming at a modal shift to active modes, public transport, and sharing mobility take effect in particular on the local level. Thus, taking also efficiency improvements of vehicles into account, the largest tank-to-wheel $\mathrm{CO}_{2}$ reduction in 2050 compared to 2015 is obtained for road modes, with approximately $-90 \%$ for vans, $-80 \%$ for cars and buses, and $-65 \%$ for trucks. Air passenger transport emissions are reduced by about $-30 \%$ in the same period by efficiency improvements and the use of biofuels.

\subsubsection{Decarbonizing the Residential and Tertiary Sector}

Today the residential and the tertiary sector are responsible for about half of the European final energy demand. The most important end-use in both sectors is the provision of space heating in buildings, which is currently dominated by the use fossil fuels such as natural gas and oil. The high share of electricity demand in the residential and tertiary sector mainly stems from the use of electric appliances and lighting as well as the demand for ventilation and cooling. However, electricity is also needed for domestic hot water generation (besides also gas and oil) and to a limited extent for the provision of space heating, e.g., via electric boilers.

To achieve ambitious $\mathrm{CO}_{2}$ mitigation levels, both sectors need to make substantial further efforts to increase building efficiency and switch to alternative heating technologies. A possible pathway for decarbonizing EU-27 and UK residential and tertiary final energy demand is shown in the High-RES centralized scenario (cf. Fig. 6.3). 


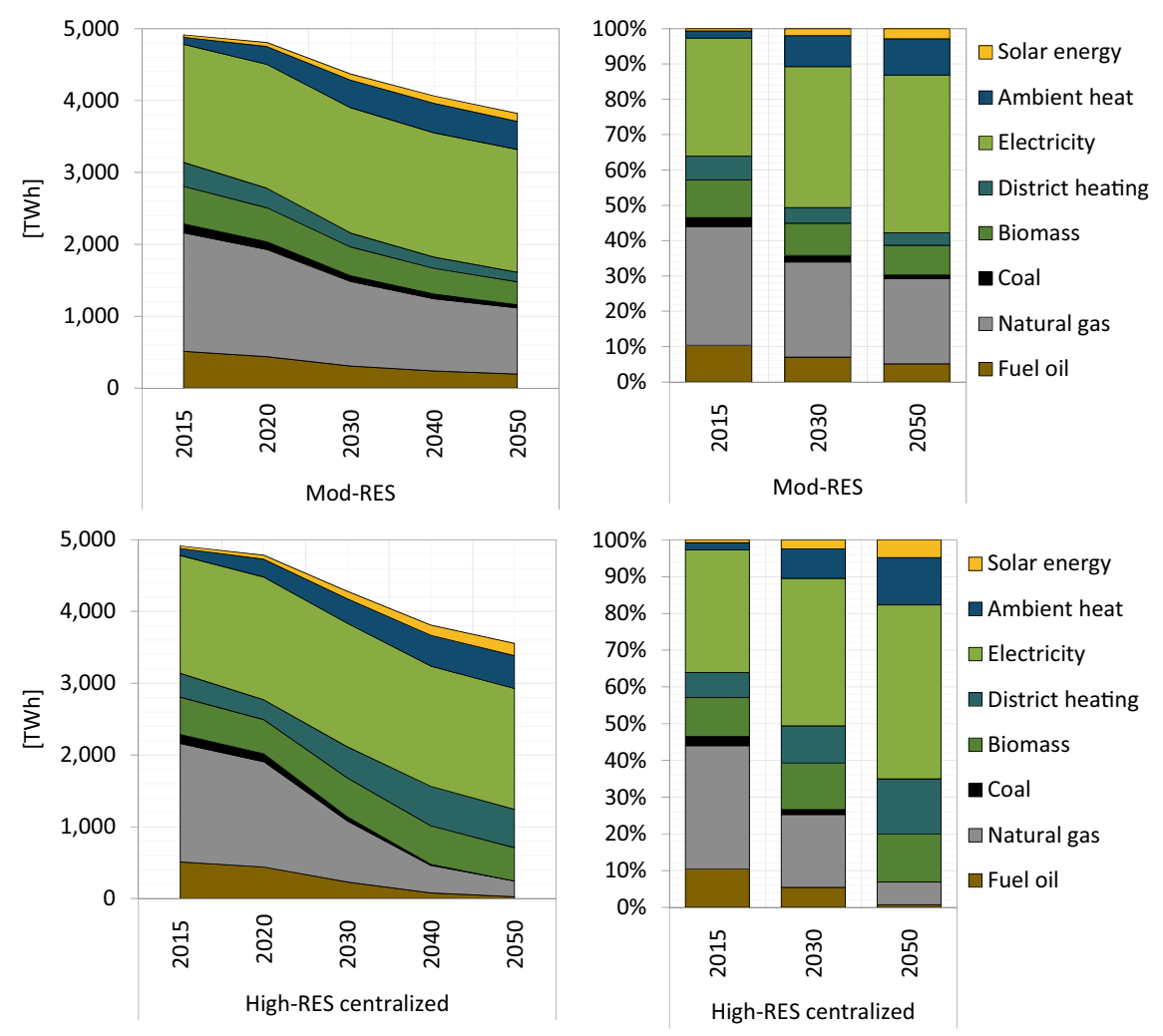

Fig. 6.3 EU-27 and UK residential and tertiary final energy demand by energy carrier and scenario in TWh (2015-2050) (Source Own illustration)

\subsubsection{Energy Efficiency}

In the tertiary and residential sector large efficiency gains already take place in the current policy Mod-RES scenario leading to a decrease in final energy demand in 2050 by $22 \%$ compared to 2015 , from $4,913 \mathrm{TWh}$ to $3,821 \mathrm{TWh}$. These improvements are mainly caused by the national implementations of existing building codes (e.g., EPBD Directive 2010/31/EU) and efficiency standards (e.g., Ecodesign Directive 2009/125/EC). The requirements of these building codes and directives are already very high but it remains partially open how strict their implementation will be. Given the cost curves for different refurbishment measures (Reiter et al. 2019), the implementation of dedicated refurbishment strategies is essential to achieve the required refurbishment rates indicated by the achieved results. Especially in the tertiary sector where building functions can often refer to multiple building code classes, this poses a challenge for the appropriate selection and application of the respective standards.

A higher adoption of efficiency classes for more products in combination with the introduction of new efficiency classes after 2025 lead, together with a deeper 
refurbishment depth complying to minimum standards, and the shorter lifetime of heating systems, to a further reduction in final energy demand by additional $6 \%$ compared to the Mod-RES scenario ( $-28 \%$ compared to 2015, from 4,913 TWh to 3,555 TWh).

The development of electricity demand until 2050 is strongly dependent on the efficiency increase and ownership rates of appliances, as well as the efficiency increase of buildings and the technology mix of heating technologies in the scenario. In the residential sector old direct electric heaters, water boilers, and night storage heaters are replaced by more efficient heat pumps leading to an increase in final electricity demand in both scenarios (18\% in Mod-RES from 1,643 TWh to 1,708 TWh, $24 \%$ in High-RES to 1,684 TWh) having a slightly stronger penetration of heat pumps in the High-RES scenarios.

Appliances in the residential and tertiary sector are the main contributor of electricity demand in 2050. White goods like refrigerators, freezers, dishwashers, and washing machines as well as ICT appliances like laptops and TVs are regulated within the European Ecodesign Directive that sets mandatory requirements for energyrelated products. Labeling and classification into efficiency classes and minimum standards of the products leads to a strong increase of the efficiency. Contrasting to the Mod-RES scenario, where the efficiency increase stems from stock turnover replacement of old products with more efficient ones complying with the current efficiency classes, the High-RES scenario includes more efficient products after 2025. Especially for dryers and refrigerators, a further efficiency increase can be observed until 2050, while for ICT appliances like laptops and TVs, the electricity consumption stays almost constant or increases, respectively, in both scenarios. The reason for this is the increase of the size of appliances and performance progress. In the tertiary sector, especially cooling demand is expected to increase due to more surface area cooled, therefore, limiting the efficiency gains due to more advanced appliances.

\subsubsection{Fuel Switch}

Although the absolute difference of final energy demand in the two scenarios is not very large, the energy carrier composition in the two scenarios is quite different. In the High-RES centralized scenario, additional support for district heating is implemented given the assumption that more district heating networks are reinforced and more buildings can be connected to it at lower costs than today. Thus, the district heating demand in the tertiary and residential sector increases by $61 \%$ compared to 2015 (from 332 to $534 \mathrm{TWh}$ ). In addition, incentives and installation subsidies for RES heating supply as well as the shorter lifetime of heating systems increase the demand for low-exergy sources like solar thermal by fourfold (from 34 to $170 \mathrm{TWh}$ ) until 2050. Due to competition with other sectors (e.g., transport and agriculture), the use of biomass is limited in the High-RES centralized scenario decreasing by $11 \%$ compared to today. The ban of oil boilers after 2030 in the residential sector, in combination with a fuel tax on gas and oil, leads to a significant reduction in fossil fuel demand for space heating. While coal is completely phase out until 2050 the 
demand for fuel oil ( $-95 \%$ compared to 2015$)$ and natural gas ( $-87 \%$ compared to 2015) decreases significantly.

\subsubsection{Impact on $\mathrm{CO}_{2}$ Emissions}

Overall emission reductions in both sectors are $89 \%$ compared to 2050 in the HighRES centralized scenario ( $84 \%$ in tertiary and $92 \%$ in residential). Especially in buildings, space heating demand is a main contributor to GHG emissions. To reduce these emissions, combined efforts in refurbishment rates, depths, and technology changes are needed. Furthermore, refurbishment is a prerequisite for the deployment of RES and electricity-based heating technologies, which are the main contributors to emission reduction in those sectors. However, reaching the EU targets includes major efforts from all actors and stakeholders as well as additional regulatory framework, especially to increase the refurbishment rate beyond the current levels. EU-wide regulations for building standards in the buildings sector are already in force and a main driver to reduce heating and consequently $\mathrm{CO}_{2}$ emissions in the long-run until 2050. To allow for a more centralized provision of renewable heat, financial incentives as well as connection regulations and strategies are needed to tap the full potential. Heat pumps can play a certain role for decarbonizing heat demand in the tertiary and residential sector, but specific support measures such as geothermal potential zones need to be managed as well as further cost reductions achieved for tapping ground sources for ambient heat gains.

\subsubsection{Decarbonizing the Industry Sector}

The industrial sector currently accounts for about a quarter of the EU-27 and UK final energy demand, mainly using fossil fuels such as gas, coal, and oil, but also electricity. Energy-intensive processes and products like, e.g., steel (iron and steel), cement (non-metallic minerals), ethylene (chemicals), and ammonia (chemicals) dominate demand and $\mathrm{CO}_{2}$ emissions in this sector. Even though, some sectors already use a high proportion of electricity and biomass (e.g., paper industry), industry needs to make significant further efforts to reduce the use of fossil fuels in the coming decades. A particular challenge is the reduction of process emissions, as these emissions can only be reduced by radical changes in the production process, product mix or the use of $\mathrm{CO}_{2}$ capture and storage. In terms of end-use, most industrial greenhouse gas emissions result from high-temperature process heat, either in the form of steam or hot water, or from direct firing of different types of furnaces. The high temperatures and the specific technological requirements limit the use of renewable energies to biomass or secondary energy (Fleiter et al. 2019; Herbst et al. 2018a, b). A possible pathway for decarbonizing EU-27 and UK industry is shown in the High-RES centralized scenario (Fig. 6.4). 

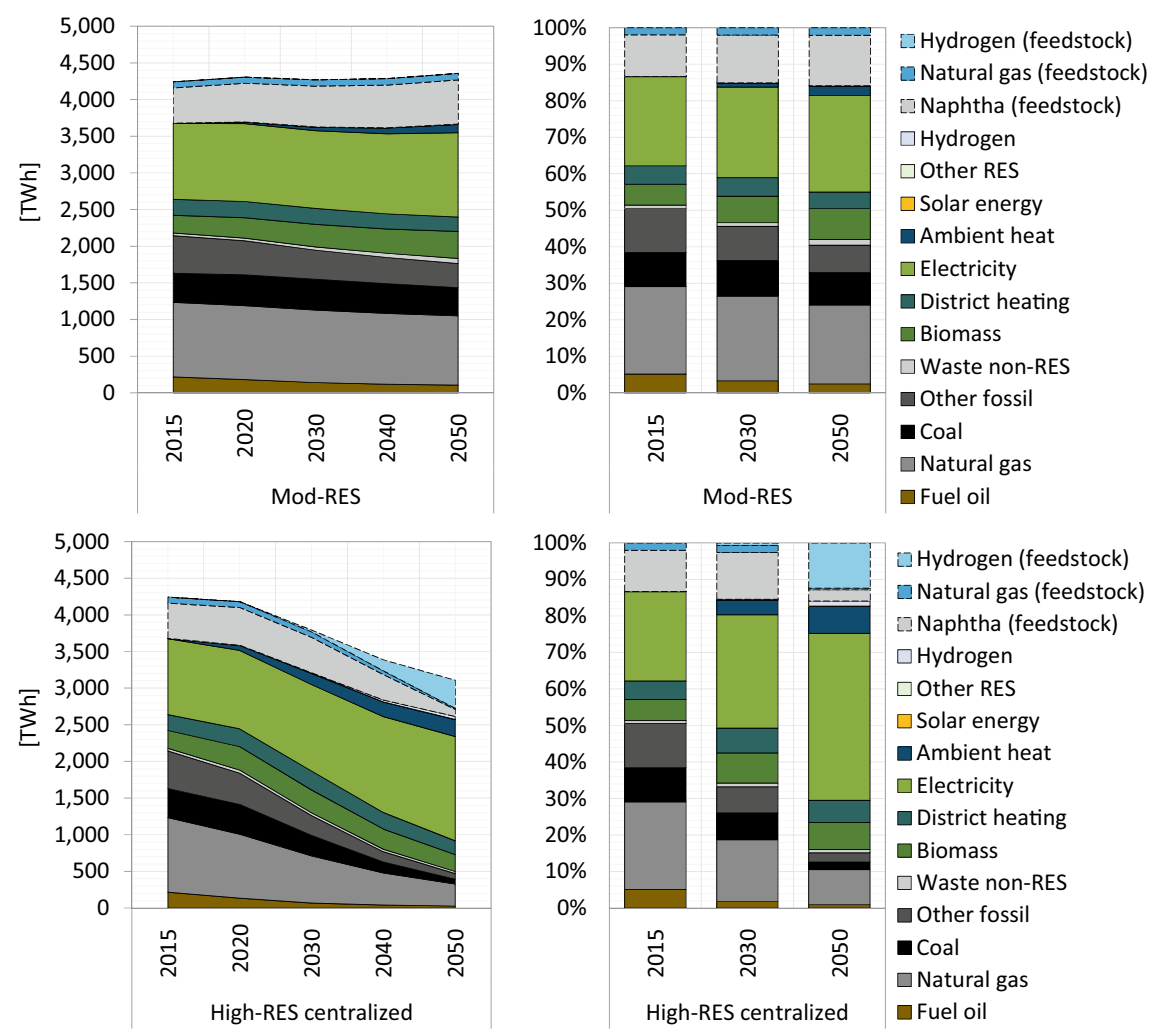

Fig. 6.4 EU-27 and UK industrial final energy demand by energy carrier and scenario in TWh (2015-2050) (Source Own illustration)

\subsubsection{Energy Efficiency}

The energy efficiency of technologies used today for the production of basic materials products like steel, cement, glass, or paper have been improved continuously over the past decades. The High-RES centralized scenario assumes a very ambitious exploitation of available energy efficiency potentials in combination with increases in material efficiency, material substitution and the recycling of materials-leading to a decrease in energy demand (incl. chemical feedstocks) in 2050 by $27 \%$ compared to 2015 , from 4,243 TWh to 3,109 TWh. Still, the improvements realized in most processes are below 20\%, indicating a limited potential for further process optimization in this sector (Herbst et al. 2018b). Exceptions are steel rolling, where new production technologies like near net shape casting or the paper production, where innovative new drying technologies can make a larger difference and materialize higher efficiency potentials. In addition to the energy-intensive basic materials processes, also cross-cutting technologies like electric motors and lighting account for a high share of total electricity demand, due to their widespread use. These 
systems are yet less optimized and remaining potentials are higher. Implementing remaining energy efficiency potentials by also optimizing the entire motor systems can further reduce demand until 2050 (Herbst et al. 2018b).

\subsubsection{Fuel Switch}

In the High-RES centralized scenario a comprehensive shift toward electricity as the dominant energy carrier in all sectors takes place in the model. This leads to an in increase in electricity demand by $37 \%$ compared to 2015, from 1,036 TWh to 1,422 TWh. Especially after 2030, the relevance of electricity as energy carrier increases significantly (46\% in 2050 of total demand), due to an economic and regulatory framework which is in favor of electricity and the market entry of innovative electricity-based production technologies.

Switching to low-carbon fuels for the generation of process heat can be a major mitigation option, given that process heat today is mainly supplied by fossil fuels. Steam and hot water generation is used across all industries and covers a temperature range of up to $500{ }^{\circ} \mathrm{C}$, which allows the use of combined heat and power (CHP) technologies. Another important field for fuel switching are industrial furnaces, which are very diverse and often work at high temperatures above $1000{ }^{\circ} \mathrm{C}$, e.g., in the cement, glass, and steel production. Fuel switching is possible, but the use of energy carriers experiences higher technical restrictions and RES are sometimes difficult to integrate. In the High-RES centralized scenario it is assumed that in 2050 steel production from blast furnaces is substituted by direct reduction of iron based on RES electrolysis and RES H2-plasma steel production combined with an increasing share of electric arc furnace steel production. In the cement and glass industry production shifts to electric kilns and furnaces and in the paper industry and other steam using industries use high-temperature heat pumps well as electric steam boilers are used where applicable.

In addition, RES hydrogen is used in the chemical industry as feedstock for the production of methanol and ammonia (384 TWh in 2050) and consequently reduces $\mathrm{CO}_{2}$ emissions for ethylene using methanol-based olefin production.

\subsubsection{Impact on $\mathrm{CO}_{2}$ Emissions}

As best available technologies and conventional fuel switch are not sufficient to decarbonize the European industry sector until 2050, the strong emissions reduction in the High-RES centralized scenario reflects the high level of ambition implied in this scenario. Direct industrial emissions decrease by $74 \%$ compared to 2015 , from 745 to $197 \mathrm{Mt}$ in 2050. Remaining emissions in 2050 mainly stem from the use of natural gas $(\sim 30 \%$ of total direct emissions in 2050$)$ and chemical reactions within the production process (process emissions: $\sim 40 \%$ of total direct emissions in 2050). The main contributor of $\mathrm{CO}_{2}$ emissions in 2050 is the non-metallic minerals sector (42\% in 2050) including emissions from smaller point sources (e.g., bricks, lime, 
ceramics) and process emissions in the cement and glass industry. Further emissions remain in the chemical industry $(16 \%)$ either from the use of natural gas or from process emissions in production. Sectors that are currently very $\mathrm{CO}_{2}$-intensive today, such as the iron and steel industry or chemical feedstock production, become almost $\mathrm{CO}_{2}$-free in 2050 .

Important enablers are innovative efficiency technologies and the direct and indirect use of electricity in the scenario. Examples are direct reduction of iron based on RES electrolysis, electric kilns and furnaces and the use of RES H2 as feedstock for methanol/ethylene and ammonia production. Innovative products like low-carbon cement sorts (using new binders) can reduce the specific energy- and process-related cement emissions by between -30 and $-70 \%$. The scenario shows that decarbonization of the industrial sector is possible - even without carbon capture and storagehowever, this requires process innovations, which currently strongly differ in maturity and distance to market, $\mathrm{CO}_{2}$-free secondary energy carriers, and innovations in material efficiency and circular economy. Besides overcoming the barriers to market entry and setting up a regulatory framework, a main challenge lies in the fast diffusion until 2050. I.e., this scenario assumes that in most energy-intensive processes, the transition is completed in 2050 , reflecting a very ambitious assumption.

\subsection{The Future Need for Demand Side Flexibility}

As explained before, efficiency improvements are likely to reduce electricity demand of end-uses. At the same time, the decarbonization of selected sectors (e.g., heating and transport) will be realized through a shift toward the use of carbon-neutral electricity, driving the diffusion of new electricity consumers. It is known that these changes in the electricity demand structure will not only affect the total amount of electricity that is consumed, but also change the shape of the system load curve ${ }^{1}$ (Boßmann and Staffell 2015; Boßmann et al. 2015). This change in the hourly electricity demand in combination with increasing levels of fluctuating electricity generation from renewable energy sources (RES), is highly likely to result in increasing level of fluctuation in the residual load (i.e., the difference between the system load and electricity generation from RES). If electricity generation from RES exceeds the actual system load, the residual load drops below zero, meaning that RES need to be curtailed in the absence of alternative flexibility options. Thus, increasing shares of RES and a transforming system load curve could drive the need for conventional generation capacities, while the utilization, and hence profitability, of new and existing RES capacities could decline. Consequently, the challenge is to find appropriate measures that increase flexibility in the electricity system and smooth the residual load in order to balance supply and demand in a cost-efficient and sustainable manner (Boßmann 2015).

\footnotetext{
${ }^{1}$ The system load curve is defined as the total hourly load of all electricity consumers in a country.
} 
In this context, information is required about the electricity consumption behavior of the individual processes in order to properly represent the technological changes inside the system load curve. Depending on the type of process, electricity load profiles are available as either yearlong (i.e., 8,760 h) profiles, typical day profiles that vary between season (summer, winter, transition) and/or weekdays (Saturday, Sunday, weekday), or temperature-dependent profiles. The latter is particular relevant in case of heating and cooling processes. The applied load profiles in the eLOAD model stem from various public sources and from the internal database of the Fraunhofer Institute for Systems and Innovation Research ISI (for details, cf. Boßmann 2015). Temperature-dependent profiles are generally applicable for various countries, since they are adjusted using local weather data. However, if typical day load profiles are not available in a specific country, these types of profiles are transferred across countries via the information form time use surveys. Such surveys report the activity (such as working, sleeping, and food preparation) of a representative sample of individual persons based on time diaries (cf. Gershuny et al. 2014, Statistika Centralbyran 2014). In this study it is assumed, that for selected processes activities correlate with electricity consumption (e.g., the activity of working with the load profile for electric vehicle charging at work) and that countries, featuring the same activity pattern, can be characterized by similar load profiles.

The application of the described process-specific load profiles in the eLOAD model results in the projection of the system load curve into the future. Figure 6.5 summarizes the effects of individual load profiles and the net effect on the system load curve in the High-RES centralized scenario in 2050. In this scenario, hydrogen is produced off-site in central large-scale electrolyzers. Therefore, hydrogen is provided directly by the energy suppliers and not included in the sectoral electricity demand. In case of decentralized scenario world this would be different (cf. Chapter 7). Note that due to an easier readability, the individual industry processes are aggregated as well as the consumption in the individual demand-side subsectors regarding the lighting, cooling, and heating processes. The most important process clusters explaining structural changes in the future system load curve are labeled. Due to the increasing electrification, the electricity demand generally increases until 2050. In particular, in the midday and evening hours, the electricity demand increases due to the charging of electric passenger cars at home and at work. In the cold season, the electricity demand by heat pumps affect the future system load. The increasing electricity demand for heating purposes is compensated to some extend by decreasing demand for lighting purposes and the classical industry processes (such as lime milling, extrusion, etc.) due to efficiency gains. Overall the system load gains in fluctuation for all considered countries and increases in temperature sensitivity in most countries, due to an increase in demand of temperature dependent heating and cooling processes.

An example of the structural changes and increasing fluctuations in the system load is depicted in Fig. 6.6, which shows the average system load curve for typical days in the EU-27 + NO + CH + UK. Overall electricity demand increases by $36 \%$ between 2014 and 2050, while the peak load increases by $51 \%$. The influence of electric vehicle charging, causing load peaks in the midday and evening hours particularly on weekdays, is clearly visible in 2050. The effect of heat pumps increasing the 


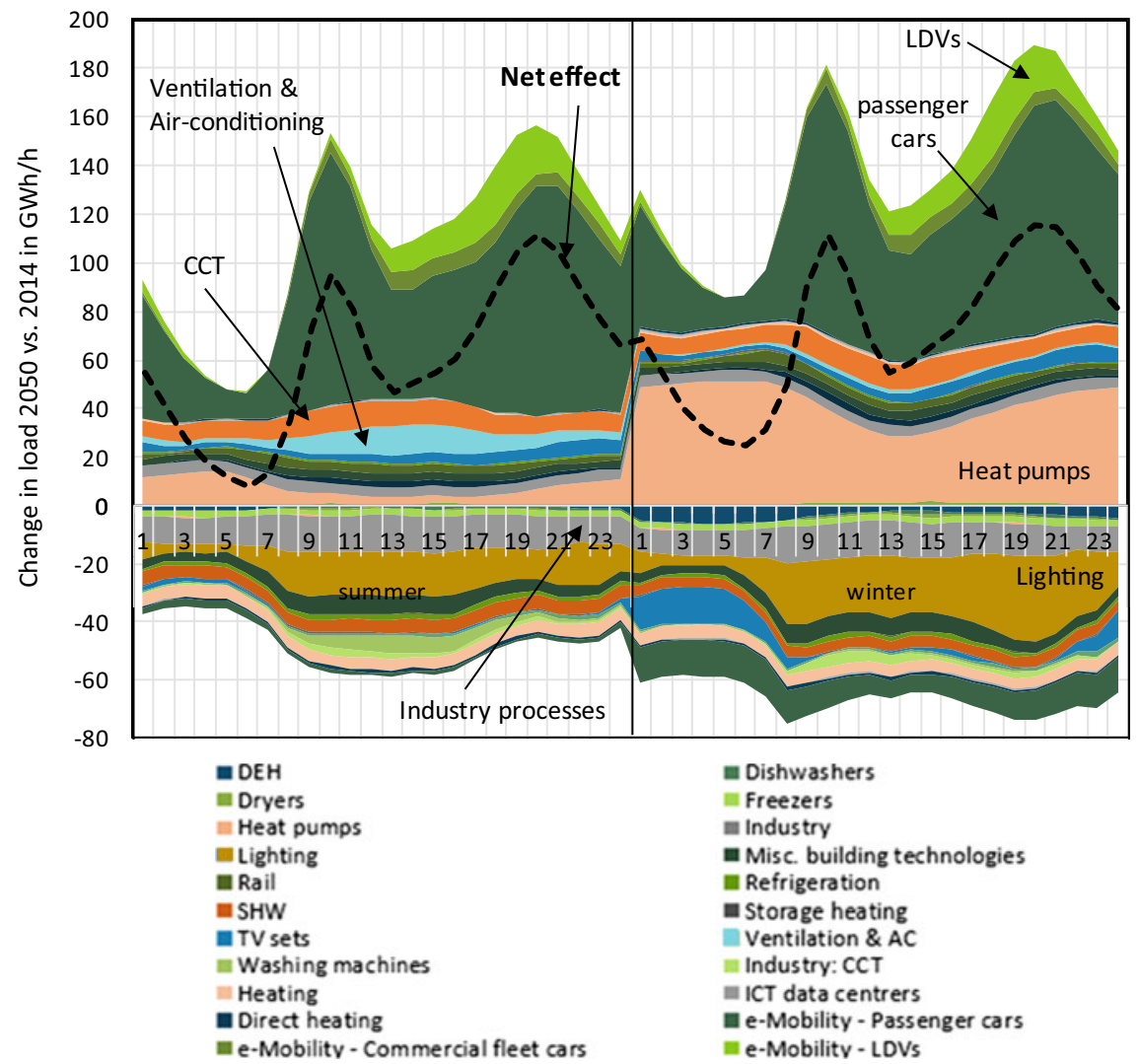

Fig. 6.5 Average load change 2050 vs. 2014 aggregation of the EU-27, Norway, Switzerland (The calculations for the hourly demand are done for these countries. Due to the lack of available data Malta is excluded from the hourly calculations), and the United Kingdom by process in summer (left) and winter (right)—High-RES centralized scenario (Source Own illustration)

average load on winter days is equally detectable, however, less pronounced due to the compensating effect of efficiency gains.

As explained earlier, increasing fluctuations drive the need for flexibility options. Furthermore, the fluctuation generation of electricity from RES leads to a highly fluctuating residual load curve that would have to be covered by conventional generation capacities if no flexibility options are available. Figure 6.7 illustrates the fluctuation in the residual load for the EU-27 + NO + CH + UK and shows the development of system load and residual load from 2020 (left part) to 2050 (right part).

Figure 6.8 shows the load changes of the EU-27 + NO + CH + UK's system load (left) and residual load (right) from one hour to the next as a load duration curve for the years 2014 to 2050. It is shown that the total electricity consumption changed by more than $\pm 50 \mathrm{GWh} / \mathrm{h}$ from one hour to the next in $2050 \mathrm{in} 382 \mathrm{~h}$. In the years before, the maximum load change was $+43 \mathrm{GWh} / \mathrm{h}(2014),+47 \mathrm{GWh} / \mathrm{h}(2030)$, 


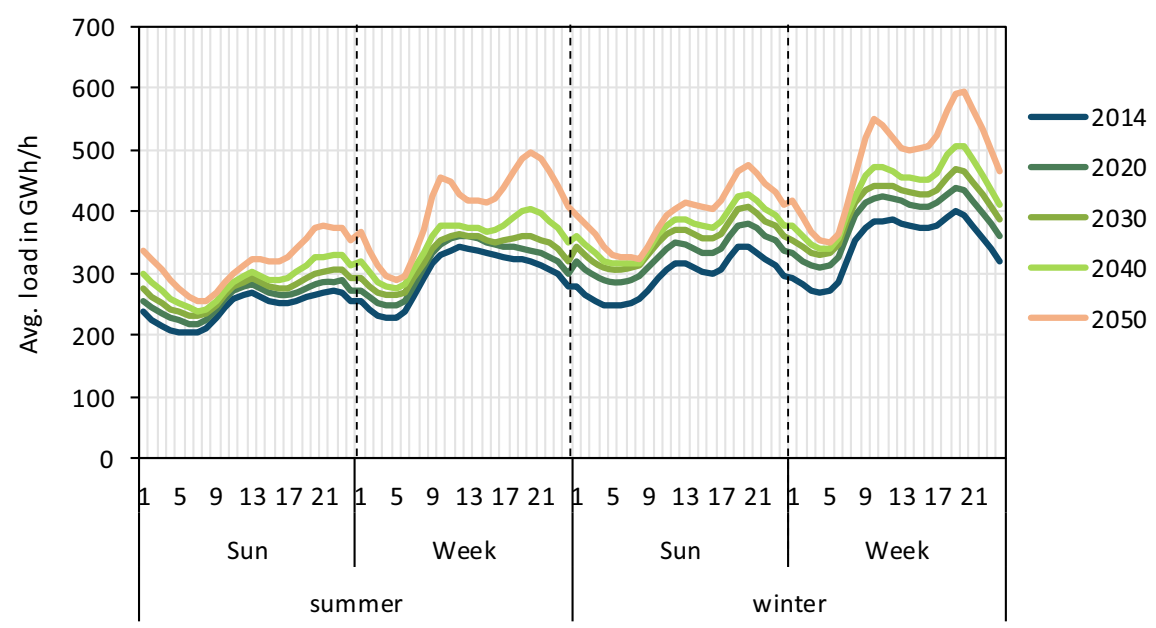

Fig. 6.6 Development of the average system load in the EU-27 $+\mathrm{NO}+\mathrm{CH}+\mathrm{UK}$ in summer and winter on Sundays and weekdays for the years 2014 to 2050 - High-RES centralized scenario (Source Own illustration)

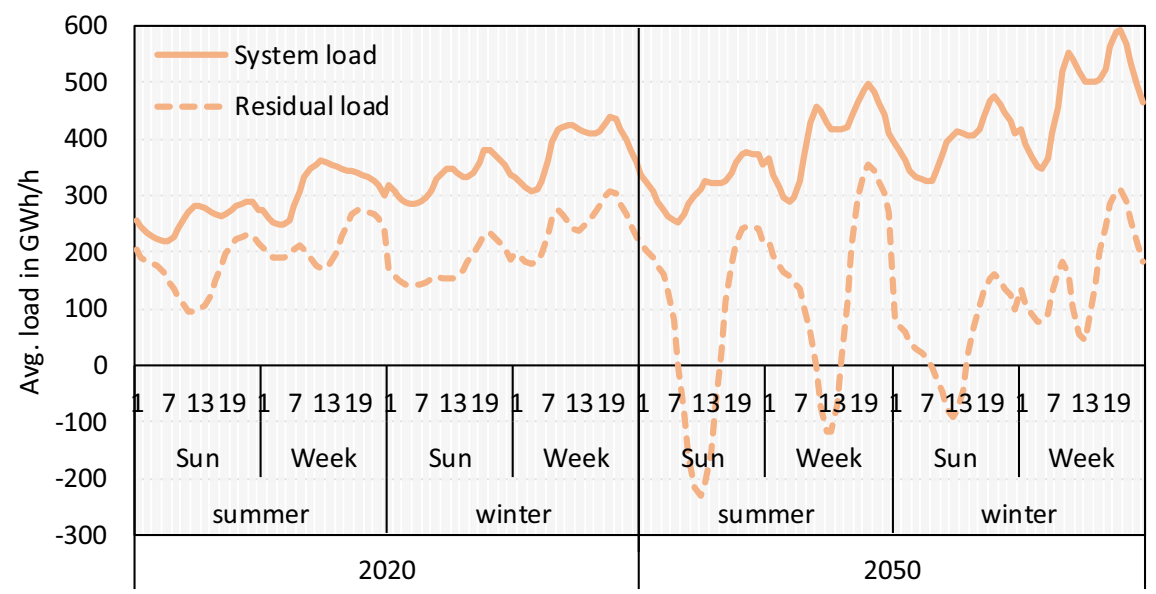

Fig. 6.7 Average system (solid line) and residual load (dashed line) of the EU- $27+\mathrm{NO}+\mathrm{CH}+$ UK in 2020 (left) and 2050 (right) - High-RES centralized scenario (Source Own illustration)

and $+50 \mathrm{GWh} / \mathrm{h}(2040)$. The load changes in the residual load increase even more dramatically to $2,127 \mathrm{~h}$ with load changes of more than $\pm 50 \mathrm{GWh} / \mathrm{h}$ (cf. Fig. 6.8).

Besides the effect of higher fluctuations in system and residual load curves, the system load curve increases in temperature sensitivity in the future in many EU countries. While energy efficiency decreases electricity demand on warm days due to more efficient ventilation and cooling systems, the increasing electrification of 

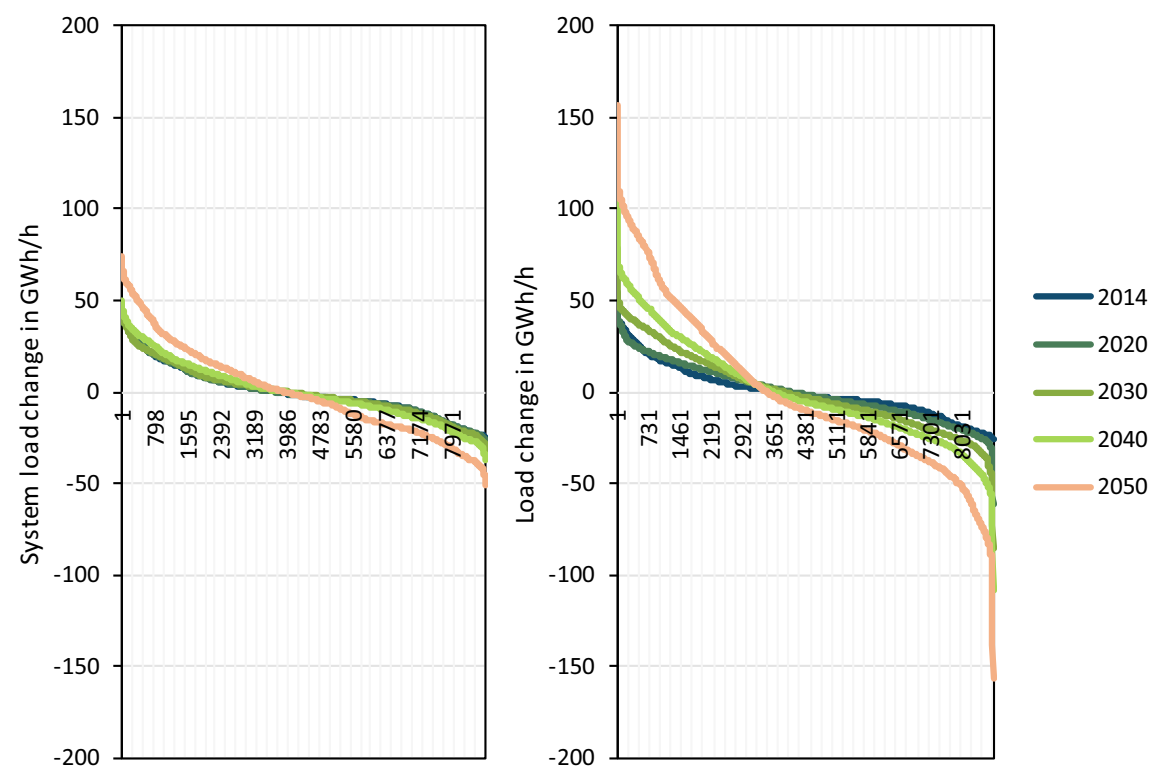

Fig. 6.8 Load duration curve for the EU28 + NO + CH's system load (left) and residual load (right) in the years 2014 to 2050-High-RES centralized scenario (Source Own illustration)

heating systems for space heating and hot water particularly in the residential and service sector leads to rising electricity consumption on cold days.

Overall the High-RES centralized scenario shows that changes in the residual and system load curve that are to be expected in a decarbonized RES energy system, which stresses the need for future demand-side flexibility. However, there is large uncertainty to which extent and at what point in time load management will be deployed throughout the EU countries. For a detailed analysis of demand-side flexibility in an ambitious mitigation scenario see Part III.

\subsection{Conclusions}

The analyses carried out in this study show that decarbonization of all demand sectors is possible until 2050. However, this requires massive efforts in all sectors and a policy framework supporting the necessary changes as well as $\mathrm{CO}_{2}$-free secondary energy carriers. In a scenario without carbon capture and storage, renewable electricity becomes the most important energy carrier in all sectors in 2050 used either directly or indirectly, e.g., as renewable hydrogen.

In the transport sector, energy demand will change significantly if GHG emission targets are met by 2050. While electrification is a key solution for road transport, blends of biofuels or synthetic fuels will play a major role in aviation and navigation. 
A combination of several strong measures and policies is required to meet the big challenge of decarbonizing a consistently growing transport demand. The diffusion of low and zero-emission drive technologies and further efficiency improvements of vehicles can contribute substantially. A large shift to the more efficient non-road modes would be even more preferable but requires a change of habits and handling processes, which is harder to achieve and predict.

In the residential and tertiary sector, refurbishment is a prerequisite for the deployment of RES and electricity-based heating technologies. Major efforts among all stakeholders are needed to increase energy efficiency in buildings and raise the refurbishment rate beyond current levels. Ambitious EU-wide regulations for building standards are already in force and the main driver to reduce heating and consequently $\mathrm{CO}_{2}$ emissions in the long-run until 2050. Heat pumps can play an important role for decarbonizing heat demand in the tertiary and residential sector, but specific support measures such as geothermal potential zones need to be managed as well as further cost reductions achieved for tapping ground sources for ambient heat gains. A higher adoption of efficiency classes for more products in combination with the introduction of new efficiency classes will also be necessary to reduce electricity demand for appliances.

In industry, the analysis has shown that today's available technologies are not sufficient for deep decarbonization of the sector. Mitigation levels in industry of more than $80 \%$ can be achieved without the use of CCS, but needs the implementation of a variety of different mitigation options including energy efficient and low-carbon production innovations, renewable-based electricity, and hydrogen (also as feedstock for the chemical industry), a comprehensive circular economy and improvements in material efficiency. In order to achieve this, the current policy mix needs to be adjusted in order to effectively support R\&D activities directed at the decarbonization of industrial production. In this context also public RD\&I funding can play an important role. A European Emission Trading minimum price path will be needed to provide more long-term clarity and the certainty for investors. $\mathrm{A} \mathrm{CO}_{2}$ tax could provide fuel switching incentives for companies outside the ETS. Boosting material efficiency and a circular economy approach along the value chain also requires a broad policy mix (e.g., measures to increase recycling rate, measures to keep $\mathrm{CO}_{2}$ price signals visible along the value chain) including targeted public procurement.

\section{References}

Boßmann T (2015) The contribution of electricity consumers to peak shaving and the integration of renewable energy sources by means of demand response-A model-based long-term scenario analysis in consideration of structural changes in electricity demand. Fraunhofer Verlag

Boßmann T, Staffell I (2015) The shape of future electricity demand: exploring load curves in 2050s Germany and Britain. Energy 90(part 2):1317-1333. https://doi.org/10.1016/j.energy. 2015.06.082 
Boßmann T, Elsland R, Klingler AL, Catenazzi G, Jakob M (2015) Assessing the optimal use of electric heating systems for integrating renewable energy sources. Energy Procedia 83(2015):130-139. https://doi.org/10.1016/j.egypro.2015.12.203

EEA (2019) Progress on energy efficiency in Europe. Indicator assessment. https://www.eea.europa. eu/data-and-maps/indicators/progress-on-energy-efficiency-in-europe-3/assessment (Accessed July 2019)

Elsland R (2017) Analysing the contribution of internal heat gains when evaluating the thermal performance of buildings. In: Littlewood J, Spataru C, Howlett R, Jain L. (eds) Smart energy control systems for sustainable buildings. Smart Innovation, Systems and Technologies, vol 67. Springer

European Commission (2011) European advanced biofuels flightpath

European Commission (2016) A European strategy for low-emission mobility. Communication from the commission to the European Parliament, the Council, the European Economic and Social Committee and the Committee of the Regions. COM (2016) 501 final

European Commission (2017) EU transport in figures-Statistical pocketbook 2017. Eurostat.

European Commission (2018) In-depth analysis in support of the Commission Communication COM (2018) 773: a Clean Planet for all A European long-term strategic vision for a prosperous, modern, competitive and climate neutral economy. Brussels

Eurostat (2017) Complete energy balances (Accessed July 2019)

Faberi S, Paolucci L, Lapillonne B, Pollier K (2015) Trends and policies for energy savings and emissions in transport. ODYSSEE-MURE 2012 project

Fermi F, Fiorello D, Krail M, Schade W (2014) Description of the ASTRA-EC model and of the user interface. Deliverable D4.2 of ASSIST (Assessing the social and economic impacts of past and future sustainable transport policy in Europe). Project co-funded by European Commission 7th RTD Programme. Fraunhofer-ISI, Karlsruhe, Germany

Fleiter T, Rehfeldt M, Herbst A, Elsland R, Klingler AL, Manz P, Eidelloth S (2018) A methodology for bottom-up modelling of energy transitions in the industry sector: The FORECAST model. Energy Strat Rev 22(2018):237-254

Fleiter T, Herbst A, Rehfeldt M, Arens M (2019) Industrial innovation: pathways to deep decarbonisation of Industry. Part 2: Scenario analysis and pathways to deep decarbonisation. ICF and Fraunhofer ISI

Gershuny J, Jones S, Fisher K (2014) Multinational Time Use Study. www.timeuse.org/mtus (Accessed 04 April 2014)

Gnann T, Klingler AL, Kühnbach M (2018) The load shift potential of plug-in electric vehicles with different amounts of charging infrastructure. J Power Sources 390:20-29

Heitel S, Krail M, Ajanovic A, Haas R, Bernath C, Sensfuß F, Lux B, Marañón-Ledesma H (2018) Ways to a cleaner and smarter transport sector. A case study report compiled within the H2020 project SET-Nav

Helms H, Lambrecht U, Hanusch J (2010) Energieeffizienz im Verkehr. In: Pehnt M (ed) Energieeffizienz: Ein Lehr- und Handbuch. Springer, Berlin and Heidelberg, pp 309-329

Herbst A, Fleiter T, Elsland R, Rehfeldt M, Reiter U (2017) Benchmarking the EU reference scenario 2016: an alternative bottom-up analysis of long-term energy consumption in Europe. In: ECEEE Summer Study Proceedings 2017, pp 159-169

Herbst A, Fleiter T, Rehfeldt M (2018a) Scenario analysis of a low-carbon transition of the EU industry by 2050: extending the scope of mitigation options. In: European council for an energy efficient economy -eceee-, Berlin: eceee 2018 Industrial Summer Study on Energy Efficiency. Proceedings: Panel: 4. Technology, products and system optimisation

Herbst A, Fleiter T, Rehfeldt M, Lux B, Pfluger B, Sensfuß F, Bernath C, Maranon-Ledesma H, Scherwath T, Holz F (2018b) D.5.5: summary report on case study: the contribution of innovative technologies to decarbonise industrial process heat. A report compiled within the $\mathrm{H} 2020$ project SET-Nav

IATA (2015) Report on alternative fuels. International air transport association, Montreal-Geneva 
Jakob M, Catenazzi G, Fleiter T (2013) Ex-ante estimation of the EU Ecodesign Directive's impact on the long-term electricity demand of the tertiary sector: eceee summer study 2013 , June 3-8, Presqu'ile de Giens, France

Klingler AL (2018) The effect of electric vehicles and heat pumps on the market potential of PV + battery systems. Energy 161:1064-1073

Krail M, Hellekes J, Schneider U, Dütschke E, Schellert M, Rüdiger D, Steindl A, Luchmann I, Waßmuth V, Flämig H, Schade W, Mader S (2019) Energie- und Treibhausgaswirkungen des automatisierten und vernetzten Fahrens im Straßenverkehr. Final report of the study on behalf of the German Federal Ministry of Transport and Digital Infrastructure. Karlsruhe, Germany

Reiter U, Palacios A, Manz P, Fleiter T, Jakob M (2019) Cost curves for heating and cooling demand reduction in residential buildings. Peer-reviewed conference contribution to ECEEE 2019 within H2020-project Heat Roadmap Europe 4

Schade W, Hartwig J, Schäfer S, Welter S, Maffii S, de Stasio C, Fermi F, Zani L, Martino A, Bellodi L (2018) The impact of TEN-T completion on growth, jobs and the environment-methodology and results. Final report Prepared for the European Commission

Statistika Centralbyran (2014) Harmonised European Time Use Survey. https://www.h2.scb.se/tus/ tus/ (Accessed 04 April 2014)

Open Access This chapter is licensed under the terms of the Creative Commons Attribution 4.0 International License (http://creativecommons.org/licenses/by/4.0/), which permits use, sharing, adaptation, distribution and reproduction in any medium or format, as long as you give appropriate credit to the original author(s) and the source, provide a link to the Creative Commons license and indicate if changes were made.

The images or other third party material in this chapter are included in the chapter's Creative Commons license, unless indicated otherwise in a credit line to the material. If material is not included in the chapter's Creative Commons license and your intended use is not permitted by statutory regulation or exceeds the permitted use, you will need to obtain permission directly from the copyright holder. 